УДК 551.332.21

ISSN 1609-0691

DOI: https://doi.org/10.17308/geology.2020.1/2512

Поступила в редакцию: 15.12.2019

Принята к публикации: 20.02.2020

Опубликована онлайн: 25.03.2020

\title{
Условно объективный цвет и оценка возможности хромостратигра- фической корреляции верхних морен Ярославского Поволжья
}

\author{
(2020 Д. Н. Киселев ${ }^{\bowtie}$, А. С. Крапивина \\ Ярославский государственный педагогический университет им. К. Д. Уиинского \\ ул. Республиканская, 108/1, 150000, Ярославль, Российская Федерация
}

\begin{abstract}
Аннотация
Введение: Цвет морен является хорошим стратиграфическим маркером, поэтому его диагностика требует описания на основе количественного подхода. Тем не менее, в практике литостратиграфической корреляции морен используется только субъективный цвет, что увеличивает вероятность ошибочной датировки четвертичных слоев. Поэтому разработка и использование новой колориметрической методологии являются весьма востребованными в практике литостратиграфических исследований.

Методика: С помощью относительного колориметрического анализа разработана методика определения объективного цвета морены и хромостратиграфической корреляции осадочных толщ. На примере верхних морен Ярославского Поволжья условно днепровского и московского возрастов, по 16 разрезам, показаны масштаб и границы изменчивости их цветовых параметров и корреляционный потенциал объективного цвета.

Результаты и обсуждение: Наибольшее диагностическое значение для определения стратиграфического типа морены имеют яркость, насыщенность и характер связи цветовых параметров. Изучение проб из опорных разрезов с двумя моренными горизонтами (Долгополка и Рыкуша) показало одинаковый масштаб различий московской и днепровской морен по параметрам объективного цвета. Условно московская морена отличается от условно днепровской в Ярославском Поволжье большим сдвигом цветового тона в красную область и повышенной яркостью, в то время как насыщенность статистически не отличается, или незакономерно изменяется географически. Распределение цветов отложений из разрезов с одним моренным горизонтом является дискретным, при этом цветовое расстояние между двумя моренами по средним величинам совпадает с разницей цвета между двумя моренами в опорных разрезах.

Заключение: Точность диагностики относительного возраста морен по объективному цвету и, соответственно, хромостратиграфической корреляции морен из разрезов с единственным сохранившимся моренным горизонтом, по имеющемуся материалу составляет около 90\%. Это позволяет рассматривать метод определения объективного цвета перспективным для решения проблемы увязки моренных горизонтов в пределах локального региона.
\end{abstract}

Ключевые слова: морена, колориметрический анализ, хромостратиграфия, Ярославское Поволжье, плейстоцен.

Для цитирования: Киселев Д. Н., Крапивина А. С. Условно объективный цвет и оценка возможности хромостратиграфической корреляции верхних морен Ярославского Поволжья // Becmник Воронежского государственного университета. Серия: Геология. 2020. №1. С. 51-58. DOI: https://doi.org/10.17308/geology.2020.1/2513

Контент доступен под лицензией Creative Commons Attribution 4.0 License.

\footnotetext{
$\bowtie$ Киселев Дмитрий Николаевич, E-mail: dnkiselev@mail.ru 


\section{Введение}

Одной из основных проблем четвертичной геологии Ярославского Поволжья, как и сопредельных районов Центральной России, является стратиграфическая увязка различных горизонтов плейстоцена, в первую очередь моренных. В Ярославском Поволжье выделяется от четырех [1] или пяти [2] до семи моренных горизонтов [3], а на территории Европейской России до девяти ледниковых стратиграфических уровней [4]. Отсутствие в морене качественных биостратиграфических маркеров (за исключением палинологических комплексов) и трудоемкость более точных методов для массового датирования приводят к необходимости использовать для корреляции осадочных образований плейстоцена, в основном, литологические признаки (гранулометрические, минералогические, петрографическое разнообразие псефитовой фракции и др.). Проводимая с их помощью литостратиграфическая корреляция часто весьма условна [5], проводится с оговорками [6] и может приводить к ошибкам в масштабе одного соседнего горизонта, реже двух горизонтов.

Из литологических признаков, использующихся для корреляции, часто недооценивается цвет, несмотря на то, что при описании морен всегда указываются их цветовые характеристики. Более того, хорошо известно, что цвет разновозрастных морен не просто уникален, но и изменяется градационно от нижних морен к верхним [1,3]. Таким образом, цвет может быть одним из наиболее выразительных стратиграфических маркеров, в особенности, если его диагностика и описание могут быть проведены на количественной основе. Необходимость такого описания повышается при сравнении стратиграфически соседних морен, сходных по цвету. Известно, что признаки тилла одного и того же горизонта вариабельны даже в пределах локальной территории, поэтому возраст стратиграфически близких морен (например, днепровского и московского возрастов, или, в еще большей степени, московского и валдайского горизонтов) может быть определен ошибочно. Так, А. И. Лобановым [3], который высоко оценивал диагностические свойства цвета, неоднократно упоминал один и тот же субъективный цвет для разных ярославских морен: коричневато-бурый - для 2-х морен (тутаевская и домниновская), красновато-коричневая - для 4-х морен (петровская, тутаевская, веригинская, брейтовская) и т.д.

Использование субъективных цветовых характеристик не позволяет описывать цвет с точностью, необходимой для решения диагностических и корреляционных задач. В этой связи становится актуальной разработка методологии количественного описания цветовых признаков морен, которая позволила бы повысить качество литостратиграфической (в данном случае - хромостратиграфической) корреляции плейстоцена.

\section{Методика и материалы}

Количественное описание цвета морен проводилось методом относительной колориметрии на основе цветоделительного подхода Альберта Манселя [7] по цветовым моделям RGB, HSV (субтрактивная) и CMYK (аддитивная). Для решения хромостратиграфических задач этот метод подробно описан и апробирован ранее на примере среднеюрских отложений [8]. Колориметрический анализ включает следующую последовательность действий:

1. Подготовка образца морены для относительной колориметрии - размельчение до однородного состояния в сухом виде;

2. Создание цифрового изображения - сканирование образца, позволяющее сохранять единые условия освещения для всей выборки;

3. Программная подготовка цветового изображения каждого образца, включающая размытие по Гауссу;

4. Программное измерение всех цветовых параметров в модели HSV и RGB;

5. Изучение распределений цветовых признаков в выборке и поиск средних величин. Цвет, определенный таким способом, рассматривается здесь как условно объективный. В практике описания литологических толщ традиционно используется субъективный цвет, выявленный визуально и охарактеризованный образными эпитетами (шоколадно-коричневый, кирпичный, красно-бурый и пр.).

Образцы валунного суглинка для колориметрического анализа собраны из двух верхних морен, условно днепровского и московского горизонтов, из естественных обнажений плейстоцена Ярославской области (Рыбинский, Тутаевский, Любимский и Ярославский районы) (рис. 1) и, для референтных целей, Московской области (табл. 1).

Среди местонахождений преобладают разрезы, в которых наблюдается единственный моренный горизонт с видимым залеганием на коренных слоях и перекрытый сверху голоценом. Среди них встречаются морены, в основном, двух типов: I - более темные, шоколадно-коричневые (условно днепровская) и II - красновато-бурые (условно московская), а также с промежуточными цветовыми характеристиками. Условность возраста упомянутых морен связана не только с отсутствием качественных датировок по большинству разрезов (разрезы табл. 1) другими методами, но и неустойчивостью стратиграфических шкал плейстоцена, как для Центральной России, так и для Ярославского Поволжья. В первом случае предметом дискуссий является число и последовательность ледниковых горизонтов в среднем неоплейстоцене [9], самостоятельность днепровского [2, 10, 11 и др.] и московского [12 и др.] горизонтов. Во втором случае неоднозначна стратиграфическая трактовка различных морен, в том числе и верхних. Например, для Ярославского Поволжья А. И. Лобановым предлагается собственная шкала плейстоцена $[3,13]$, при этом им категорически отвергается присутствие валдайского горизонта на большей части данной территории. 
Табл. 1. Перечень разрезов, где были отобраны образцы морены для колориметрического анализа, и их характеристики.

[Table 1. List of sections where moraine samples were taken for colorimetric analysis, and their characteristics.]

\begin{tabular}{|c|c|c|c|c|c|c|}
\hline \multicolumn{2}{|l|}{$\begin{array}{c}\text { Разрез } \\
\text { [section] }\end{array}$} & $\begin{array}{l}\text { Район или } \\
\text { область } \\
\text { [district or } \\
\text { region] }\end{array}$ & $\begin{array}{c}\text { Тип } \\
\text { морены } \\
\text { [type of } \\
\text { moraine] }\end{array}$ & $\begin{array}{c}\text { Наличие кон- } \\
\text { такта с корен- } \\
\text { ными слоями } \\
\text { [Contact with } \\
\text { pre-Quaternary } \\
\text { beds] } \\
\end{array}$ & $\begin{array}{c}\text { Положение } \\
\text { опробованной } \\
\text { морены (сверху } \\
\text { вниз) [роsition of } \\
\text { the tested moraine } \\
\text { (top to bottom)] }\end{array}$ & $\begin{array}{l}\text { Кол-во моренных } \\
\text { горизонтов в разрезе } \\
\text { [the number of mo- } \\
\text { raine horizons in the } \\
\text { section] }\end{array}$ \\
\hline д. Мостово & \multirow{7}{*}{ 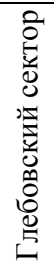 } & Рыбинский & II & есть (мел) & первая & 1 \\
\hline д. Горохово & & Рыбинский & II & есть (мел) & первая & 1 \\
\hline д. Захарьино & & Рыбинский & II & есть (мел) & первая & 1 \\
\hline с. Глебово (северная часть) & & Рыбинский & II & есть (мел) & первая & 1 \\
\hline с. Глебово (южная часть) & & Рыбинский & II & есть (мел) & первая & 1 \\
\hline д. Юрино & & Рыбинский & II & есть (юра) & первая & 1 \\
\hline д. Бабурино & & Рыбинский & II & есть (юра) & первая & 1 \\
\hline \multicolumn{2}{|c|}{ р. Крутец - 1 (Рыбинск, л.берег) } & Рыбинский & I & не видно & первая & 1 \\
\hline \multicolumn{2}{|c|}{ р. Крутец - 2 (Рыбинск, л.берег) } & Рыбинский & I & не видно & первая & 1 \\
\hline \multicolumn{2}{|c|}{ Рыбинск - Тоговщина (пр. берег) } & Рыбинский & I & есть (юра) & вторая & 2 \\
\hline \multicolumn{2}{|l|}{ д. Сельцо-Воскресенское } & Рыбинский & II & есть (мел) & первая & 1 \\
\hline \multicolumn{2}{|l|}{ Тутаев - 1 (левый берег) } & Тутаевский & I & не видно & вторая & 2 \\
\hline \multicolumn{2}{|l|}{ p. Долгополка } & Тутаевский & I & не видно & третья & 3 \\
\hline \multicolumn{2}{|l|}{ р. Долгополка } & Тутаевский & II & не видно & вторая & 3 \\
\hline \multicolumn{2}{|l|}{ р. Рыкуша-1 (Тутаев, пр. берег) } & Тутаевский & $\mathrm{I}$ & не видно & вторая & 2 \\
\hline \multicolumn{2}{|c|}{ р. Рыкуша-2 (Тутаев, пр.берег) } & Тутаевский & II & не видно & первая & 2 \\
\hline \multicolumn{2}{|l|}{ д. Голубково (р. Обнора) } & Любимский & II & есть (?неоген) & первая & 1 \\
\hline \multicolumn{2}{|c|}{ Крестовский карьер (Ярославль) } & Ярославский & II & есть (мел) & первая & 1 \\
\hline \multicolumn{2}{|l|}{ Карьер Еганово } & Московская & II & есть (юра) & первая & 1 \\
\hline
\end{tabular}

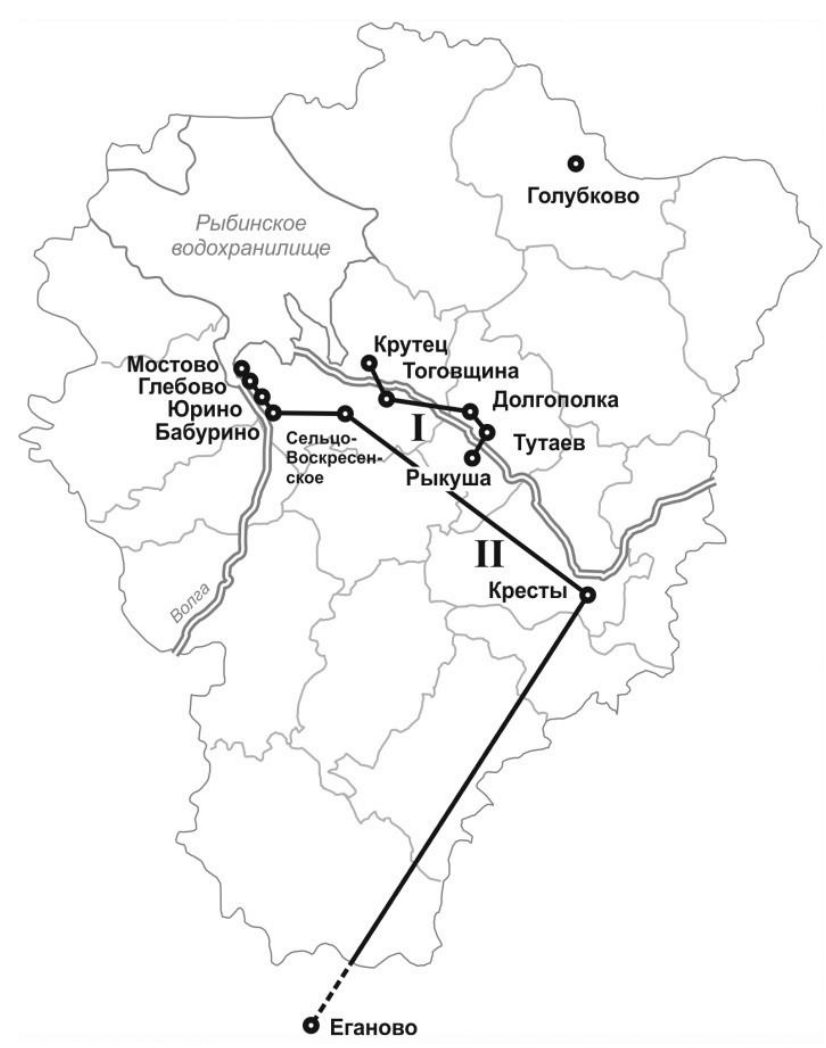

Рис. 1. Расположение разрезов плейстоцена в Ярославской области, в которых собраны пробы морен на колориметрический анализ. Черными линиями обозначены направления профилирования цветовых признаков морен типа I и II (см. рис. 3).
[Fig. 1. The location of the Pleistocene sections in the Yaroslavl region, in which moraine samples were collected for colorimetric analysis. The black lines indicate the directions of profiling color signs of moraines of type I and II (see Fig. 3).]

Разрезы с единственным горизонтом морены в Ярославской области преобладают, и их увязка с небольшим числом опорных разрезов имеет значение для построения адекватной палеогеографической картины и решения других задач четвертичной геологии. Принадлежность морен одного типа из разных разрезов к одному стратиграфическому горизонту может быть доказана латеральным прослеживанием в пределах локального географического сектора. К таким относится, в первую очередь, Глебовский сектор (профиль д. Мостово - д. Бабурино), и в меньшей степени - Тутаевский (р. Долгополка - Тутаев - р. Рыкуша).

Также взяты образцы из разрезов с двумя моренами (Долгополка и Рыкуша), чье стратиграфическое положение более определенное из-за наличия последовательности морен типов I и II. Такие образцы служат реперами. В опорном разрезе Долгополка возраст трех морен (днепровской, московской и калининской) надежно установлен как по самим моренам, так и по межледниковым отложениям [15], поэтому он служит превосходным репером для корреляции с другими разрезами. Из двух нижних морен разреза Долгополка взяты пробы, которые использованы для референтных целей.

Основная цель данного исследования - определить точное цветовое различие между стратиграфи- 
чески близкими моренами. Для ее выполнения необходимо изучить вариабельность цветовых признаков (цветовой тон $\mathrm{H}$, яркость В и насыщенность $\mathrm{S}$ по модели HSB) в пределах одного моренного горизонта, географическую изменчивость цветовых признаков в пределах рассматриваемой территории и определить средние величины цветовых признаков для разновозрастных морен. Ниже изложены предварительные результаты, полученные по ограниченной выборке.

\section{Результаты}

Цветовая характеристика морен на основе цветовой модели HSB (HSV) производится раздельно путем оценки распределений по трем составляющим.

Цветовой тон (Нue, Н). Характеристика, означающая положение определяемого цвета внутри области цветового круга и единицей измерения - угловая величина в 1 градус. Минимальное значение 1 соответствует красному цвету, 30 - оранжевому, 60 - желтому, 120 - зеленому, 180 - голубому, 240 - синему, 300 - фиолетовому, 360 - малиновому.

Значение Н в изучаемой выборке находится в диапазоне 27-37, что соответствует оранжевой области спектра, а красная (диапазон 1-20) и желтая (диапазон 40-60) вообще не характерны для данной выборки. 8 образцов находятся в красно-оранжевой области (диапазон 20-30), а 11 - в желто-оранжевой (диапазон 30-40). Распределение образцов по данному параметру является непрерывным (рис. 2а) и, соответственно, морены различных типов не имеют существенных отличий по этому признаку. Небольшие отличия связаны лишь с легким смещением плотности выборки в различные области цветового тона: у морены I типа $12 \%$ проб приходится на красно-оранжевую область, а у морен II типа таких проб только 64\% (рис. 2a). Следовательно, морены II типа в среднем чуть более красные, приблизительно на $5 \%$.

Насыщенность (Saturation, S) - это степень интенсивности цветового тона по отношению к черному, серому и белому цветам, которые имеют минимальную насыщенность, равную 1, а максимальную - 100. Насыщенность цвета осадочных пород смешанного минералогического состава (в основном, обломочные или хемогенные) определяется количеством и соотношением пигментирующих минераловхроматофоров, обладающих высокой насыщенностью в чистом виде. Соответственно, значение насыщенности может отражать содержание минералогических пигментов.

В выборке морен насыщенность изменяется непрерывно (без видимой дискретности) от 50 до 90, что означает хорошую насыщенность (рис. 2a). При этом 7 образцов находится в интервале средней насыщенности (диапазон 33-66), а 12 - высокой (диапазон 66-100). В среднем, морены II типа на 7\% более насыщенные, чем морены I типа.

Яркость (Brightness, Br) или величина цвета (Value, V) - параметр, означающий, насколько данный цвет
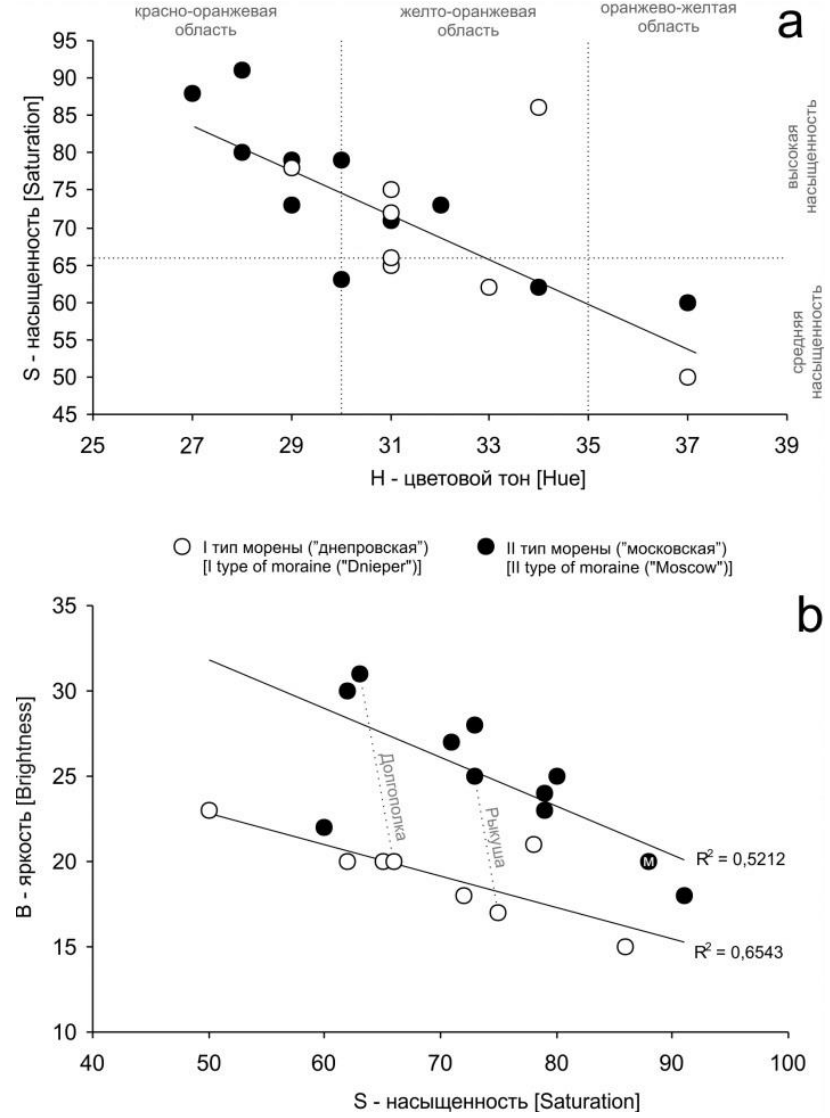

Рис. 2. Распределение параметров цвета морен на корреляционных диаграммах: а - насыщенность - цветовой тон; б насыщенность - яркость. Серым пунктиром связаны значения проб из одного разреза, значком "м" обозначена проба из Московской области.

[Fig. 2. Distribution of moraine color parameters on correlation diagrams: a - saturation - color tone; $\mathrm{b}$ - saturation - brightness. The gray dashed lines indicate the values of samples from one section, the " $m$ " symbol indicates the sample from the Moscow region.]

отклоняется от черного. Минимальная яркость, равная 1, означает полностью черный цвет, максимальная, 100 - полное отсутствие черного. Цвет с $\mathrm{Br}=100$ может быть как белым (минимальное S), так и спектральным с максимальным S.

Яркость морен находится в диапазоне 15-31, что соответствует темной области (1-33), при этом распределение является дискретным: выборка образцов морены I отделяется диастемой от выборки морены II с очень небольшим перекрытием - 2 образца из 19. Это особенно хорошо видно на корреляционной диаграмме по двум параметрам (рис. 2б). В среднем, морены II типа на 23 \% более яркие, чем морены I типа.

Все три признака находятся в обратной зависимости в отношении друг к другу с высоким коэффициентом корреляции, как для пары цветовой тоннасыщенность, так и для пары насыщенность-яркость (рис. 2). Первая корреляционная пара дает непрерывное распределение, а вторая - дискретное. Соответственно, вторая пара признаков имеет диагностическое значение для распознавания разных типов морен. 


\section{Обсуждение результатов}

Несмотря на изменчивость колориметрических показателей, морены различного типа могут быть распознаны по комплексу цветовых признаков, в первую очередь по яркости, и их корреляционным зависимостям. Объективный цвет для различных морен характеризуется следующим образом:

морена I типа - темная желто-оранжевая (с примесью красно-оранжевой), средней или высокой насыщенности;

морена II типа - светлая красно-оранжевая (с примесью желто-оранжевой) средней или высокой насыщенности.

В субъективных характеристиках, использующихся в литературе, им соответствует шоколаднокоричневый и красно-бурый цвет.

Наибольшая изменчивость характерна для яркости и насыщенности, что, вероятно, определяется вариациями содержания красящих пигментов (табл. 2). Пестрый состав морен зависит также и от наличия мини отторженцев коренных пород, которые преобладают в более древних моренах (в данном случае II типа). В Ярославской области это, в основном, триасовые пестроцветные глины (голубовато-синего и фиолетового цвета), серые и черные юрские глины и юрские зеленоватые глауконитовые песчаники. Из-за таких примесей цвет морены может значительно меняться локально, поэтому морены разного возраста становятся близкими по цвету в отдельных пробах. В этой связи становится очевидным, что для стратиграфических целей цвет морены следует опробовать не по одному образцу, а по представительной выборке.

В референтных разрезах Долгополка и Рыкуша нижние морены (тип I) отделены от верхних (тип II) по яркости широкой диастемой (рис. 2б, серая пунктирная линия), размер которой составляет 69\% от максимального диапазона значений всей выборки. Поскольку возраст нижней и средней морен в разрезе Долгополка достоверно установлен (днепровский и московский), мы можем быть уверены, что такая разница в яркости отображает стратиграфические различия. Следовательно, пробы морен из остальных разрезов, находящиеся в той же области тренда, что и пробы из референтных разрезов, могут с большой долей вероятности рассматриваться как днепровские или московские. Исключение составляют всего 2 пробы из 19 , в связи с чем вероятность стратиграфической ошибки при использовании данного метода составляет не более $10 \%$.

Сильное отклонение значений яркости в единственной пробе днепровской морены происходит из разреза Крутец и обусловлено частым присутствием в теле морены мини отторженцев (в основном, триасовых глин и глауконитовых песков юры). Две другие пробы из того же разреза показали нормальные значения.

Вторая отклоняющаяся проба происходит из морены типа II разреза Мостово (глебовский сектор). Ее отклонение от нормы может быть следствием разных причин, в том числе и погрешностью опробования. Как утверждает А. И. Лобанов [3], «не только расчистка обнажения может резко изменить цвет морены, но и описание керна через две-три недели после его подъема». Поэтому, для того чтобы снизить вероятность ошибки при построении цветовых корреляционных моделей лучше использовать измерения не отдельных проб (как в данной работе), а средних величин по каждому разрезу.

Таким образом, после проведенного анализа цвета мы можем констатировать, что морена типа I, с вероятностью 0,9 (или 90\%), относится к днепровского горизонту, а типа II - московскому (по [11, 14, 15 и др.]), которые в других стратиграфических моделях соответствуют вологодскому и московскому горизонтам [10] или петровской и домниновской толщам [13]. Это позволяет планировать изучение изменчивости свойств морены в пространстве.

Географическая изменчивость цвета морен обоих типов может быть оценена методом комплексного профилирования (рис. 3). При сравнении цветовых профилей видно, что в обоих случаях наиболее изменчиво поведение насыщенности, что, по-видимому, обусловлено случайными вариациями состава морены из-за различных примесей. Остальные параметры цвета ведут себя более или мене стабильно. Это показывает, что на локальных территориях в одном и том же моренном горизонте цветовые характеристики меняются незначительно, что соответствует тезису А. И. Лобанова [3] о сохранении одинаковой окраски морены на значительных площадях. Следовательно, цвет может быть использован, как минимум, для внутрирегиональной корреляции моренных толщ, в данном случае в пределах Ярославского Поволжья. Насколько стабилен цвет морены за пределами одного региона - вопрос, ответ на который требует дополнительных исследований. Предварительно, нами опро-

Табл. 2. Средние величины и показатель изменчивости морен типа I

("днепровская") и типа II ("московская") по колориметрическим показателям.

[Table 2. Average values and variability index of moraines of type I (Dnieper) and type II (Moscow) according to colorimetric indicators.]

\begin{tabular}{|l|c|c|c|c|}
\hline \multirow{2}{*}{} & \multicolumn{2}{|c|}{$\begin{array}{c}\text { Cpeднеe } \\
\text { [average] }\end{array}$} & \multicolumn{2}{c|}{$\begin{array}{c}\text { Коэффициент вариации, \% } \\
\text { [the coefficient of variation, \%] }\end{array}$} \\
\cline { 2 - 5 } & Тип I & Тип II & Тип I & Тип II \\
\hline Цветовой тон $(\mathrm{H})$ & 32.12 & 30.45 & 5.92 & 7.26 \\
\hline Насыщенность $(\mathrm{S})$ & 69.25 & 74.45 & 12.27 & 10.9 \\
\hline Яркость $(\mathrm{Br})$ & 19.25 & 24.81 & 10.06 & 12.52 \\
\hline
\end{tabular}



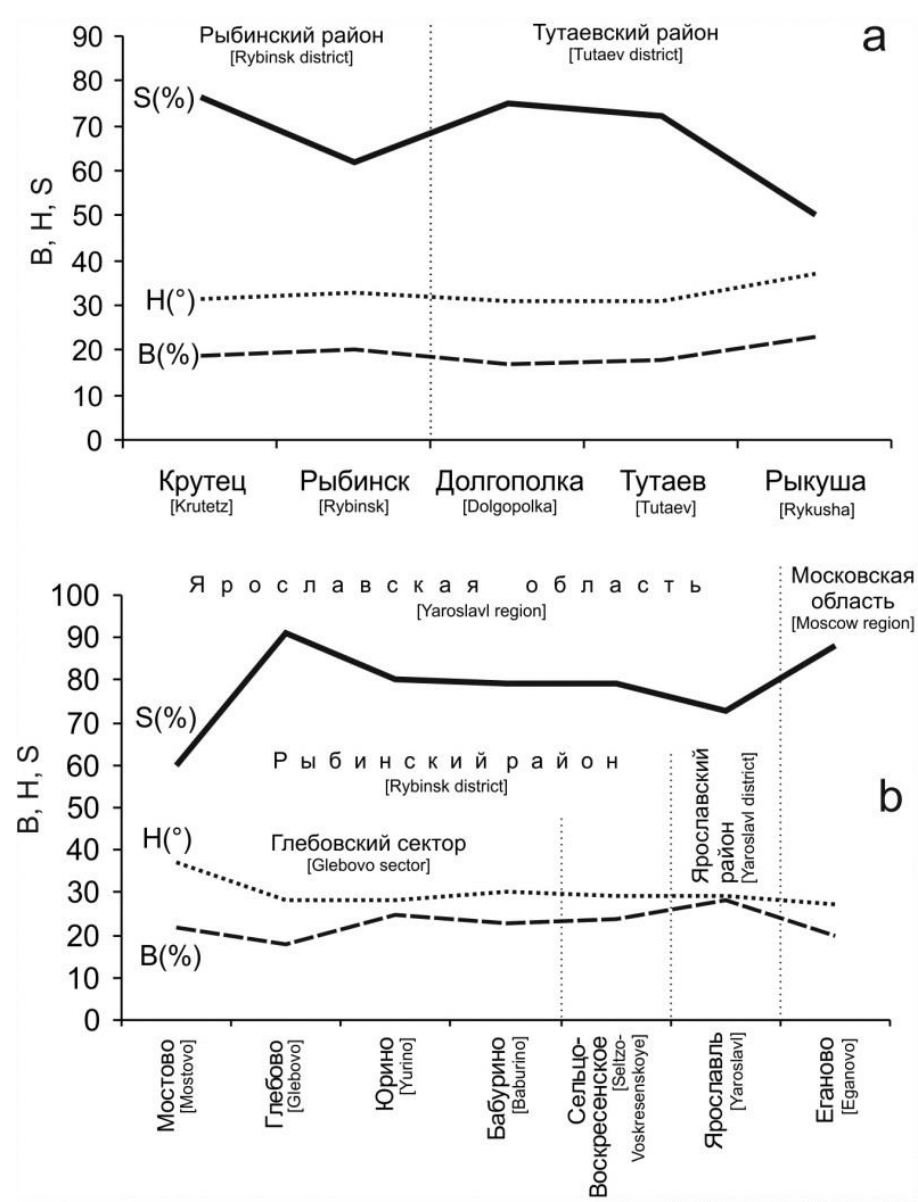

Рис. 3. Географическое изменение параметров цвета морен типа I (a) и II (б). Положение профилей на карте см. на рис. 1.

[Fig. 3. The geographical change in the color parameters of moraines of type I (a) and II (b). The position of the profiles on the map, see fig. 1.]

бован один образец московской морены из Московской области (табл. 1), который находится в том же пространстве цвета, что морена II типа Ярославской области (рис. 2б, рис. 3). Это позволяет предполагать, что цвет морены в пределах одного стратиграфического горизонта географически весьма стабилен.

\section{Заключение}

Предварительные результаты показывают, что метод относительной колориметрии дает возможность различать близкие по возрасту морены, несмотря на существующую локальную изменчивость цветовых характеристик. Соответственно, этот метод может быть использован для стратиграфических целей. Тем не менее, для успешного его использования необходимы дополнительные исследования: а) изменчивости цвета морен из одного слоя и одного разреза на более представительной выборке; б) географической изменчивости цвета морен внутри региона на большем числе разрезов; в) изменчивости цвета одновозрастных морен в нескольких регионах, что позволит, по возможности, выделить хромостратиграфические фации; г) корреляций цвета морены с другими литологическими признаками, что повысит диагностические возможности метода и позволит использовать относи- тельный колориметрический анализ для решения других задач.

Конфликт интересов Авторы декларируют отсутствие явных и потенциальных конфликтов интересов, связанных с публикацией настоящей статьи.

\section{ЛИТЕРАТУРА}

1. Новский В. А. Плейстоцен Ярославского Поволжья. М.: Наука, 1975. 236 с.

2. Шик С. М., Бирюков И. П Четвертичные отложения Ярославского Поволжья // Проблемы стратиграфии четвертичных отложений и палеогеографии Ярославского Поволжья. Материалы симпозиума. М.: ГЕОС, 2001. C. 1-8.

4. Величко А. А., Морозова Т. Д., Писарева В. В., Фаустова М. А. Хроностратиграфические подразделения четвертичной системы по материалам исследования ледниковых и перигляциальных областей Восточно-Европейской равнины // Общая стратиграфическая шкала России: состояние и проблемы обустройства. Всероссийское совещание. 23-25 мая 2013 г., Геологический институт РАН, г. Москва. Москва, ГИН РАН, 2013. С. 379-381.

5. Лаврушин Ю. А. Строение и формирование основных морен материковых оледенений. М.: 1976. 237 с.

6. Лаврушин Ю. А. Разрезы четвертичных отложений на левом берегу Волги между Угличем и Мышкиным // Проблемы стратиграфии четвертичных отложений и палеогеографии Ярославского Поволжья. Материалы симпозиума. М.: ГЕОС, 2001. С. 78-79.

7. Munsell A. H. A Pigment Color System and Notation // The American Journal of Psychology. 1912. V. 23. no. 2. pp. 236-244.

8. Киселев Д. Н., Охапкина Е. А. Предварительные результаты апробации «хромостратиграфического» метода в изучении келловея в опорном разрезе у д. Черменино (р. Унжа, Кологривский район) // Юрская система России: проблемы стратиграфии и палеогеографuи. V Всероссийское совещание: научные материалы. В. А.Захаров (отв. ред.), М. А. Рогов, Б. Н. Шурыгин (редколлегия). Екатеринбург: ООО "Издательский дом "ИздатНаукаСервис", 2013. С. 109-115.

9. Антонов С. И., Рычагов Г. И., Судакова Н. Г. Среднеплейстоценовые оледенения центра Русской равнины. Проблемы стратиграфии и палеогеографии // Бюллетень комиссии по изучению четвертичного периода. 2004. № 65. С. 5-16.

10. Шик С. М. Некоторые проблемы стратиграфии и палеогеографии квартера // Бюллетень комиссии по изучению четвертичного периода. 2008. № 68. С. 41-49.

11. Судакова Н. Г. Актуальные дискуссионные вопросы о проявлении ледниковых событий в центре Русской равнины // Бюллетень комиссии по изучению четвертичного периоda. 2012. № 72. C. 60-72.

12. Писарева В. В., Чеботарева Н. С. О ранге и возрасте московского ледникового покрова // Бюллетень комиссии по изучению четвертичного периода. 1986. № 55. С. 45-51.

13. Лобанов А. И. Корреляционные признаки тиллов центра России // Вестник Воронежского государственного университета. Серия: Геология. 2002. № 2. С. 27-40.

14. Бреслав С. Л. Четвертичная система. Геология СССР. T. IV, часть 1. Геологическое описание. М.: Недра, 1971. С. 489-636.

15. Судакова Н. Г. Опорный разрез позднего плейстоцена Долгополка // Проблемы стратиграфии четвертичных отложений и палеогеографии Ярославского Поволжья. М.: ГЕОС. 2001. С. 61-67. 
UDC 551.332.21

ISSN 1609-0691

DOI: https://doi.org/10.17308/geology.2020.1/2512

Поступила в редакцию: 15.12.2019

Принята к публикации: 20.02.2020

Опубликована онлайн: 25.03.2020

\title{
Conditionally objective colour and assessment of the possibility of chromostrati- graphic correlation of the upper moraines of the Yaroslavl Volga region
}

\author{
C2020 D. N. Kiselev ${ }^{凶}$, A. S. Krapivina \\ Yaroslavl State Pedagogical University named after K. D. Ushinsky, \\ 108/1 Respublikanskaya st., Yaroslavl 150000, Russian Federation
}

\begin{abstract}
Introduction: The colour of moraines is a good stratigraphic marker, therefore its diagnostic requires a description based on a quantitative approach. However, in the practice of the lithostratigraphic correlation of moraines, only the subjective colour is used. This increases the probability of erroneous dating of the Quaternary beds. Therefore, the development and use of a new colorimetric methodology is highly demanded in the practice of lithostratigraphic studies.

Methodology: The methodology for determining the objective colour of a moraine and chromostratigraphic correlation of sedimentary strata was developed using relative colorimetric analysis. Based on the example of the upper moraines of the Yaroslavl Volga region of the conditionally Dnieper and Moscow ages, based on 16 sections, the scale and boundaries of the variability of their colour parameters and the correlation potential of objective colour were shown.

Results and discussion: The brightness, saturation, and nature of the relationship of colour parameters had the highest diagnostic value for determining the stratigraphic type of moraine. The study of samples from reference sections with two moraine horizons (Dolgopolka and Rykusha) showed the same scale of differences between the Moscow and Dnieper moraines in terms of objective colour parameters. Conditionally, the Moscow moraine differs from the conditionally Dnieper in the Yaroslavl Volga region by a large shift of the colour tone into the red region and increased brightness, while the saturation was not statistically different or geographically irregularly changed. The colour distribution of sediments from sections with one moraine horizon was discrete, the average colour distance between two moraines coincided with the colour difference between two moraines in the reference sections.

Conclusions: The accuracy of diagnostics of the relative age of moraines by objective colour and, accordingly, the chromostratigraphic correlation of moraines from sections with the only preserved moraine horizon, according to the available material, was about $90 \%$. This allowed us to consider the method for the determination of objective colour as being promising for solving the problem of matching moraine horizons within the local region.
\end{abstract}

Keywords: moraine, colorimetric analysis, chromostratigraphy, Yaroslavl Volga region, Pleistocene.

For citation: Kiselev D. N., Krapivina A. S. Conditionally objective colour and evaluation of the chromostratigraphic correlation possibility of upper moraines of the Yaroslavl Volga region. Vestnik Voronezhskogo gosudarstvennogo universiteta. Seriya: Geologiya = Proceedings of Voronezh State University. Series: Geology, 2020, No. 1, pp. 51-58. DOI: https://doi.org/10.17308/geology.2020.1/2513

Conflict of interests: The authors declare the absence of obvious and potential conflicts of interest related to the publication of this article).

Dmitry N. Kiselev, E-mail: dnkiselev@mail.ru 


\section{REFERENCES}

1. Novsky V. A. Plejstocen Yaroslavskogo Povolzh'ya [Pleistocene of the Yaroslavl Volga region]. Moscow, Nauka publ., 1975, 236 p. (in Russ.)

2. Shik S. M., Biryukov I. P. Chetvertichnye otlozheniya Yaroslavskogo Povolzh'ya [Quaternary deposits of the Yaroslavl Volga region]. Problemy stratigrafii chetvertichnyh otlozhenij $i$ paleogeografii Yaroslavskogo Povolzh'ya [Problems of stratigraphy of the Quaternary deposits and paleogeography of the Yaroslavl Volga region]. Symposium materials. Moscow. GEOS publ., 2001, pp. 1-8. (in Russ.)

4. Velichko A. A., Morozova T. D., Pisareva V. V., Faustova M. A. Hronostratigraficheskie podrazdeleniya chetvertichnoj sistemy po materialam issledovaniya lednikovyh i periglyacial'nyh oblastej Vostochno-Evropejskoj ravniny [Chronostratigraphic units of the Quaternary system based on materials from studies of glacial and periglacial regions of the East European Plain]. Obshchaya stratigraficheskaya shkala Rossii: sostoyanie i problemy obustrojstva [General Stratigraphic Scale of Russia: State and Problems of Arrangement]. All-Russian meeting. May 23-25, 2013, Geological Institute of the Russian Academy of Sciences, Moscow. Moscow, GIN RAS, 2013, pp. 379-381. (in Russ.)

5. Lavrushin Yu. A. Stroenie i formirovanie osnovnyh moren materikovyh oledenenij [The structure and formation of the main moraines of continental glaciations]. Moscow, 1976, 237 p. (in Russ.)

6. Lavrushin Yu. A. Razrezy chetvertichnyh otlozhenij na levom beregu Volgi mezhdu Uglichem i Myshkinym [Sections of Quaternary sediments on the left bank of the Volga between Uglich and Myshkin]. Problemy stratigrafii chetvertichnyh otlozhenij $i$ paleogeografii YAroslavskogo Povolzh'ya [Problems of stratigraphy of Quaternary sediments and paleogeography of the Yaroslavl Volga Region]. Symposium materials. Moscow, GEOS publ., 2001, pp. 78-79. (in Russ.)

7. Munsell A.H. A Pigment Color System and Notation. The American Journal of Psychology, 1912, vol. 23, no. 2, pp. 236244.

8. Kiselev D. N., Ohapkina E. A. Predvaritel'nye rezul'taty aprobacii «hromostratigraficheskogo» metoda $\mathrm{v}$ izuchenii kelloveya v opornom razreze u d. Chermenino (r. Unzha, Kologrivskij rajon) [Preliminary results of "chromostratigraphic" method approvals for the studying of the Callovian in the Tchermenino reference section (Unzha river, Kologriv area)]. Yurskaya sistema Rossii: problemy stratigrafii i paleogeografii [Jurassic System of Russia: Problems of stratigraphy and paleogeography]. Fifth All-Russian meeting. September 23-27, 2013, Tyumen. Scientific materials. V.A. Zakharov (ch. ed.), M.A. Rogov, B.N. Shurygin (eds.). Yekaterinburg: "ID "IzdatNaukaServis" LLC, 2013, pp. 109-115. (in Russ.)

9. Antonov S. I., Rychagov G. I., Sudakova N. G. Sredneplejstocenovye oledeneniya centra Russkoj ravniny. Problemy stratigrafii i paleogeografii [Middle Pleistocene glaciations of the center of the Russian Plain. Problems of stratigraphy and paleogeography]. Bulletin of the Commission for the Study of the Quaternary. 2004, no. 65, pp. 5-16. (in Russ.)

10. Shik S. M. Nekotorye problemy stratigrafii i paleogeografii kvartera [Some problems of stratigraphy and paleogeography of a Quarter]. Bulletin of the Commission for the Study of the Quaternary, 2008, no. 68, pp. 41-49. (in Russ.)

11. Sudakova N. G. Aktual'nye diskussionnye voprosy o proyavlenii lednikovyh sobytij v centre Russkoj ravniny [Current controversial issues in glacial stratigraphy and palaeogeography in Central Russia]. Bulletin of the Commission for the Study of the Quaternary, 2012, no. 72, pp. 60-72. (in Russ.)

12. Pisareva V. V., Chebotareva N. S. O range i vozraste moskovskogo lednikovogo pokrova [On the rank and age of the Moscow ice sheet]. Bulletin of the Commission for the Study of the Quaternary. 1986, no. 55, pp. 45-51. (in Russ.)

13. Lobanov A. I. Korrelyacionnye priznaki tillov centra Rossii [Correlation signs of tills in the center of Russia]. Vestnik Voronezhskogo gosudarstvennogo universiteta. Seriya: Geologiya $=$ Proceedings of Voronezh State University. Series: Geology, 2002, no. 2, pp. 27-40. (in Russ.)

14. Breslav S. L. Chetvertichnaya sistema [The Quaternary System]. Geology of the USSR. T. IV, part 1. Geological description. Moscow, Nedra publ., 1971, pp. 489-636. (in Russ.)

15. Sudakova N. G. Opornyj razrez pozdnego plejstocena Dolgopolka [Dolgopolka reference section of the Late Pleistocene]. Problems of stratigraphy of the Quaternary sediments and paleogeography of the Yaroslavl Volga Region. Moscow, GEOS publ., 2001, pp. 61-67. (in Russ.)
Киселев Дмитрий Николаевич - к.г.-м.н., доцент, Ярославский государственный педагогический университет им. К. Д. Ушинского, Ярославль, Российская федерация; E-mail: dnkiselev@mail.ru;

ORCID http://orcid.org/0000-0001-9425-2759

Крапивина Анастасия Сергеевна - студент, Ярославский государственный педагогический университет им.

К.Д. Ушинского, Ярославль, Российская федерация; E-mail: krapivinanastja1999@gmail.com

Авторы прочитали и одобрили окончательный вариант рукописи.
Dmitriy N. Kiselev - PhD in Geol-Min., Associate Professor, Yaroslavl State Pedagogical University named after

K. D. Ushinsky, Yaroslavl, Russian Federation;

E-mail: dnkiselev@mail.ru;

ORCID http://orcid.org/0000-0001-9425-2759

Anastasiya S. Krapivina - student, Yaroslavl State Pedagogical University named after K. D. Ushinsky, Yaroslavl, Russian Federation;

E-mail: krapivinanastja1999@gmail.com

All authors have read and approved the final manuscript. 